\title{
The Influence of Place on Everyday Life: Observations of Persons with Dementia in Regular Day Care and at the Green Care Farm
}

\author{
Gunn Eva Solum Myren"1,2, Ingela Enmarker1,3, Ove Hellzen², Ellen Saur ${ }^{4}$ \\ ${ }^{1}$ Centre for Care Research, Mid-Norway, Steinkjer, Norway \\ ${ }^{2}$ Department of Nursing Science, Mid-Sweden University, Sundsvall, Sweden \\ ${ }^{3}$ Faculty of Health and Occupational Studies, University of Gävle, Gävle, Sweden \\ ${ }^{4}$ Department of Education, Norwegian University of Science and Technology, Trondheim, Norway \\ Email: gunn.e.myren@nord.no
}

How to cite this paper: Myren, G.E.S., Enmarker, I., Hellzen, O. and Saur, E. (2017) The Influence of Place on Everyday Life: Observations of Persons with Dementia in Regular Day Care and at the Green Care Farm. Health, 9, 261-278.

https://doi.org/10.4236/health.2017.92018

Received: November 22, 2016

Accepted: February 12, 2017

Published: February 15, 2017

Copyright (c) 2017 by authors and Scientific Research Publishing Inc. This work is licensed under the Creative Commons Attribution International License (CC BY 4.0).

http://creativecommons.org/licenses/by/4.0/

\begin{abstract}
Day care services for persons with dementia are becoming an important aspect of community services. Place, therefore, becomes vital concerning how such establishments are organized regarding both the physical and social environment and the programs that are offered. The aim of this study was to describe the influence of place on everyday life in two different organized daycare services for persons with dementia. Based on observations and informal conversations with persons with dementia and staff members at a green care farm and a regular day care, we used an inductive manifest content analysis. The analysis reveals a main category: enabling and collaboration in daily life. The results are discussed in light of Goffman's analysis of the structures of social encounters from the perspective of the dramatic performance. The main findings in this study involve how place contributes to enabling activities and collaboration between participants and staff, as it influences participants' ability to achieve an active or passive role in everyday life at the day care services.
\end{abstract}

\section{Keywords}

Day Care Services, Green Care, Dementia, Place, Goffman

\section{Introduction}

As the leading cause of dependency, dementia has no cure and results in declines in functional ability in everyday life amongst older people [1]. Informal caregivers play an important role in caregiving for persons with dementia. However, there is a risk for increased caregiver burden, and several studies stress the importance of reducing this burden [2] [3]. To reduce institutionalization and help 
persons with dementia remain at home for as long as possible and to prevent health issues amongst informal caregivers, there is a trend towards increased attention to and use of day care services as an important area of community services [4] [5] [6]. The purpose of this kind of service is to offer meaningful activities to persons with dementia while providing respite care for informal caregivers [7] [8] [9]. In people with dementia, both verbal expressions, e.g. short sentences and non-verbal behaviours, and adjustments in body posture, eye contact, touching and so on, are central to communication and collaboration [10]. Day care services create a framework for social interaction that promotes opportunities as well as limitations regarding social interaction that influences everyday life in such a program [11]. Hence, place is vital for persons with dementia and their everyday life in day care services. According to Diaz Moore (2014), place plays a powerful role throughout the life span and particularly in later life. The Ecological Framework of Place (EFP), developed from Lawton and Nahemow's ecological model of ageing (1973), defines place as: "socio-physical milieu involving people, the physical setting, and the program of the place, all catalyzed by situated human activity and fully acknowledging that all four may change over time" ([12], p. 183). In the work "The Presentation of Self in Everyday life" [13], Goffman sees the world as a stage, where we are both performers and audience for each other. Combining Goffman's expressions, frontstage and backstage, we might be able to understand better in which ways place influence on the everyday life of persons with dementia in day care services. Several studies have demonstrated the relationships that exist among the environment, staff, and residents in institutions such as asylums and prisons [11] [14], long-term care facilities [15] [16], and other facilities such as regular day care organizations [17] [18] [19]. Most of these studies have focused on environment (including both physical and social dimensions) and quality of life in regard to persons with dementia [20] [21] [22] [23] or place identity as an important component of older people's self-identity [24] [25] [26]. However, research about day care services for persons with dementia and the influence of these places on their everyday life remains limited in Scandinavia and Norway, and especially day care for persons with dementia at green care farms.

The aim of this study was to describe the influence of place on the everyday life of persons with dementia in day care services.

\section{Methods}

The study used a qualitative descriptive design with an inductive manifest content analysis based on observations and informal conversations with persons with dementia and staff at a green care farm and a regular day care.

\subsection{Setting and Sampling}

The fieldwork took place at two different organized day care services in the same municipality in the central region of Norway. To be included in the study, the day care services had to offer services for persons with dementia (from here on 
called participants) still living at home. Nurses specialized in dementia care assisted with the recruitment of participants in day care services. The same nurse obtained the written consent. People with mild dementia (12 participants) were asked for their informed consent, while in cases of moderate dementia (2 participants), next of kin were asked for such consent. All of the 14 participants and 9 staff members in the two day care services, consented to participate in the study. The persons with dementia, 7 women and 7 men, had differing symptoms of the condition and varied in age from 56 - 86 years old. Mini Mental State Examination (MMSE) score for the persons with dementia varied from 16 to 25 points (mean MMSE score $=21$ ), and their initial diagnoses ranged from 1 to 5 years prior to the study. Staff members included the farm owner, nursing assistants, and nursing students; the majority were women, and one staff member working at the green care farm was a man. To be included in the study, the day care services had to offer services for persons with dementia (from here on called participants) still living at home.

The green care farm was socially oriented and located in a rural area outside a suburban town. In all, 8 participants, 2 males and 6 females, attended two days each week. Their average age was 77 years. The green care farm has offered such services since 2010. The main building's ground floor served as the location for the day care. Both the staff and participants used all of the rooms, including the restrooms. In the kitchen, an old kitchen table was placed in front of a window, and we could watch birds visiting the bird feeder outside. A 3-foot-tall stone wall separated the kitchen area from the living room. A stove was placed along the wall, and two large armchairs sat in front of the fireplace. Behind the armchairs were two couches with a table in the middle. There was no television in any of the rooms. Since it is a private home, the environment and interior reflected this with, for example, a photo of the farm owner's children on the wall, children's toys, and musical instruments such as a piano, violin, guitar, and trumpet. There were old and antique items placed around inside the house, but these appeared natural in the environment. The stable on the farm acts as an extension area of the day care services. There were 12 horses at the farm, as well as several cats, two goats and a dog.

The regular day care was located in a suburban town. It was care oriented and located in an area with different kinds of municipal health and welfare services for elders, such as sheltered housing and special care units for persons with dementia. Daily attendance included 6 participants, 5 males and 1 female, for two days each week. Their average age was 68 years old. The day care opened in a newly renovated building in 2014 but has been in operation for the past 10 years. The physical environment was designed to meet a universal design. Each room was large and open, had a high ceiling with a ventilation unit, and the walls and ceilings were all painted white. The dayroom was divided in two, and the dayroom, which was used most, included sofas grouped at both ends of the room. In the middle, there was a door leading out to a patio that was also arranged as a smoking area with deck chairs. Half of this wall was made of large, glass windows with a view to the garden and patio. A TV was placed in front of one of the 
sofa groupings. Pictures of the royal family hung on the wall. From the dayroom, one could enter an open entry area that was separated by a glass door. This area had features that resembled the olden days, like an old slop sink, a hallstand with lots of old hats and old-fashioned furnishings, i.e., a three-piece living room set and coffee table. In this area, there was an office where staff could hang their coats and leave personal belongings. In addition, it was used as a break room where staff could take a coffee break and read the newspaper. There were separate restrooms for the staff and the participants. In the kitchen, a large dinner table was placed in a corner with eight chairs.

\subsection{Data Collection}

Data collection was inspired by Diaz Moore's Ecological Framework of Place [12], but in addition, we used an inductive entrance to ensure broader data collection. Data were collected for both day care services by two researchers (GESM \& ES) between February and April 2014 and in a second period by one researcher (GESM) from January to March 2015. According to Polit and Beck (2004: 337) observational methods "... involve obtaining data through the direct observation of phenomena", allowing observers to gather a variety of information in the natural settings to describe people's actions in everyday life [27]. Participant observation, non-participant observation, and informal conversations were used to explore the cultural influences and interactions between day care services environments, participants, and staff [27]. In order to grasp a holistic frame of the physical and social environment (embodied and emplaced knowledge), we also included the sensory environment in our observations, with attention to sensory perception and one's own embodied experience [28] [29]. For instance, as researchers, we could sense a feeling of waiting for something to happen. The observations captured represent not only decor, colors, smells, sounds, social interactions, movements, etc. but also a lack of these. The researchers conducted observations and held informal conversations with both participants and staff at both day care services two days each week. We covered the whole day, including bringing participants to and from day care services by bus. Each day we spent in the field lasted approximately 4 - 5 hours. As observers, we participated in all of the practical activities that felt natural, such as meals, knitting, domestic work, music activities, etc. We also helped in the stable at the green care farm. Besides observing the physical environment, social and environmental observations focused on the interactions between the participants and staff, their behaviours, and their use of language; these included the contacts and interactions between participants and the animals at the farm. Field notes were written regularly during each day of observation, primarily by withdrawing to another room [27]. Apart from the data that emerged from participant observations, the first researcher (GESM) also took notes during informal conversations with participants and staff. Using our senses in different ways motivated us to ask questions about what we observed or did not observe. Questions that included the words "why" and "how" thus became central to our fieldwork. 


\subsection{Ethics}

Social Science Data Services in Norway approved the study (no: 31594), and it was carried out in accordance with the World Medical Association Declaration of Helsinki [30]. All names were changed in order to preserve the informants' anonymity. We chose to withdraw to another room to write field notes because we were told that some participants attending day care services could become a bit suspicious about us observing them specifically.

\subsection{Data Analysis}

The data were analyzed using qualitative content analysis as described by Graneheim and Lundman (2004) [31]. The analysis started during the fieldwork but was also conducted in relation to the context. By treating the materials as text and reading through the field notes and notes about informal conversations several times, we were able to re-experience the sensory and emotional reality of the research situation [28], and become familiar with the written material, thereby achieving an overall impression and sense of the texts [31]. Through this approach, we could involve sensory and embodied memories such as a look, a movement, a sound, participants' and staff members' locations in the rooms or around the table, etc. In the process of analysis, questions including words such as "who", "where", and "what" became more central in order to describe phenomena [32]. The manifest content, or what the text is saying, is presented in categories [31] (Table 1). Hence, this text was divided into meaning units that were condensed into a description close to the text, and then abstracted and labeled with codes to reflect the content. All codes were then compared for similarities and differences, resulting in five sub-categories, three categories, and a main category. To ensure rigor in the data analysis, all four authors were involved in it.

\section{Results}

The analysis resulted in a main category, enabling and collaboration in daily life, and three categories: physical environment with the sub-categories homelike environment and institutional environment. The second category, social environment, had the sub-category social interactions, and the third category, activities, had the sub-categories: active in daily activities and passive in daily activities.

\subsection{Enabling and Collaboration in Daily Life}

This study revealed a main category that mirrored the influence of place in the everyday life of persons with dementia in day care services. This main category both reflects and depends on the physical and social environment and what kinds of activities take place.

\subsubsection{Physical Environment}

The first category is about how physical environment contributes to shaping the two different care settings, one with a homelike environment and the other that 
Table 1. Examples of analysis.

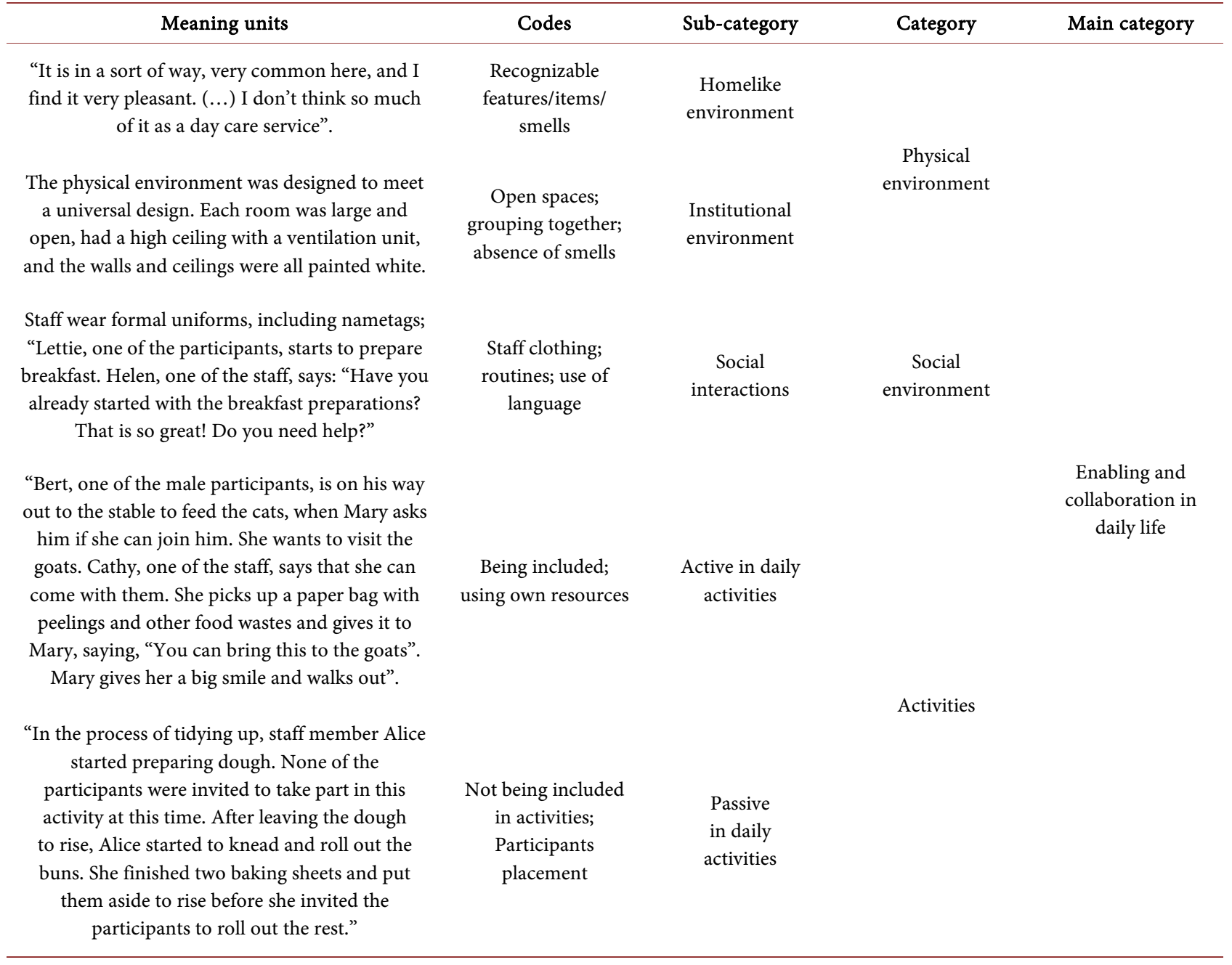

appears to have a more institutional environment. Variations in the physical environments lead to different sensory impressions and experiences of everyday life in day care services.

1) Homelike environment

Informal conversations with both staff and participants reveal that they express satisfaction and a sense of belonging at the green care farm with its homelike environment. One of the participants expressed it this way: "It is in a sort of way, very common here, and I find it very pleasant. Everything happens so naturally. I don't think so much of it as a day care". The staff expressed how new participants were easily acclimatized and included in the environment. The old-style setting appeared very natural in the homelike environment. Meals were eaten around the old kitchen table, and since it was a bit too small, participants and staff had to sit closely together. A "spin-off" effect of this was that all of them naturally touched each other; conversations took place about everyday life, with scattered comments about passing the butter, jam, cheese, etc. The constricted space around the table led to the inclusion of all and helped the staff provide attention to each participant, as they could see and hear each one. An 
informal conversation with one of the staff members confirmed this when she said:

"Sitting tight together around the breakfast table, without having to think about the time passing by, we have a unique possibility to establish close and safe contact with the participants and to build on trust and respect. It is a good way to get acquainted with each one and get to know them better".

The participants noticed and recognized the old-fashioned furnishings like the old bed, and they talked often about the olden days. One day, a participant grabbed my hand while telling me:

"My brother and I used to share a bed like this in my childhood. (He points his finger towards the old bed.) The bed was placed in the corner in the main room because then we could get some heat from the stove during winters. We used to lay head to feet, and we had to share one blanket. I often woke up because my brother used to turn around and around in the bed. He even used to take the blanket away from me, that brat (laughter)."

Since there was no TV at the green care farm, the open fire in the stove and even the bird feeder functioned as common places to sit down and watch for both participants and staff. While some preferred to sit in front of the stove and watch the flames in silence, others preferred to sit down around the kitchen table, where they chatted about the birds and their activity at the feeder. Usually this resulted in a quick walk outside to feed the birds with breadcrumbs left from breakfast. The sensory environment was rich, with smells from the kitchen, e.g. from baking crispbread, apple pie, or freshly brewed coffee, colourful candlelight and flowers placed around inside the house, and music from the radio or tape recorder. The farm owner's dog also triggered the participants to go outside and cuddle and pet it, or they asked if the dog could come inside when he barked. Some participants smoked, and they could go outside and sit down in wicker chairs in the garden.

2) Institutional environment

Observations in the regular day care revealed an institutional environment with minimal sensory impressions from both the interior and the architecture. Amy (a participant) confirmed this by expressing that she did not want to stay and that she felt bored, but she pointed out that she liked the other participants and the staff. On several occasions, she had arranged for her husband to come and pick her up before the end of the day. Some spaces were designated as participants' spaces (restrooms), staff spaces (e.g. restroom and break room), and neutral spaces such as the dayroom and, at particular times, the kitchen. One staff space was a room like a nursing station where staff could withdraw, hang their coats, and leave their personal belongings. The participants had no such place to withdraw if they so desired. One of the staff members, Astrid, said that they try their best to make it homey and cozy, but the architecture and design with the open space and white walls made this challenging. For that reason, they had placed several old items in each room. For example, in the kitchen, there was an old trough placed on the floor and an old white apron with lace hanging 
on the wall. In the dayroom, pictures of the royal family hung on the wall, and some of the tables had tablecloths and potted plants. The staff found the architecture useful in the way that it allowed them to keep an eye on all of the participants, both inside and outside, particularly if participants went out for a smoke or a short walk. Astrid further said:

“... anyway, the large open space gives us an opportunity to keep an eye on the participants. One day, two of them asked if they could take a walk outside. 'That's okay,' I said. 'But you have to follow the path around the house so you don't get lost'. I watched them through the windows, just in case... They were so proud when they came back after managing walking the route alone".

In this day care environment, everybody could see everyone else, and for the participants, there was no place to withdraw from the rest of the group, except when using the restroom. If the participants sat down on the old-fashioned sofa at the other end of the building, they could be seen through the glass door. If they went out to the patio for a smoke, they could be observed through the large, glass windows. Since the open dayroom had separated sofa groupings and a few chairs placed around the room, participants did not place themselves in the same sofa groupings but rather sat at a distance from each other.

\subsubsection{Social Environment}

The second category focuses on how time schedules and routines contribute to different kinds of social interactions. The regular day care was located near sheltered housing, and the staff told us that several of them worked at both places. The staff members were dressed in formal uniforms, including work shirts, and some wore nametags. We noticed only a little small talk and conversation between the staff and the participants except for at meals and activities. We did not observe physical contact between the staff and the participants, such as holding hands or hugging. Such contact seemed to occur more naturally and spontaneously at the green care farm, where staff dressed informally without nametags or uniforms.

1) Social interactions

Staff at both day care services told us that there was a minimum of two staff members at work every day because this provided flexibility for enabling activities. The places differ in how social interactions take place and in what kinds of ways. The regular day care appeared to have a professional relationship toward participants and followed a more progressive time schedule, while at the green care farm, relationships tend to demonstrate closer bonding between staff and participants, as well as more collaboration and engagement between participants. As an example, we illustrate from the field notes:

"Lettie (a participant) starts to prepare breakfast after just entering the day care. Helen, one of the staff, says: 'Have you already started with the breakfast preparations? That is so great! Do you need help?' Lettie: 'Yes, somebody has to cut bread and get the spreads from the fridge.' (...) Helen starts laying spreads from the fridge on the table while she is humming along with melody played on 
the radio. Shortly after, Dina, another of the participants, asks if there is any need for her help. Helen says she could help by cutting cucumbers and tomatoes in slices. After a while, all three of them are humming to the same melody on the radio, while they prepare the breakfast table".

Both places have weekly schedules with meals and activities at regular times, and participants were expected to follow these routines. Dinner was served as a final common activity for the day around 2 p.m. at both locations. Yet one of the day care services was more flexible regarding time schedules, such as when to have a coffee break. At the green care farm, coffee breaks took place when someone asked for them or occurred spontaneously after, for example, baking cakes or other activities. This flexibility was also present during activities, which could include going beyond the planned schedule but with no hesitation or stress experienced by those involved. Instead, the program was adapted during the day, and if there was not enough time for an activity, it could be moved to the next day or activities could be added if there was additional time. In the regular day care, activities occurred more precisely, and if there was time left over, participants and staff spent time in front of the TV or just waited for the next activity. We did not observe any of the participants asking for coffee between activities at the regular day care. When gathered around the kitchen table, the staff at both locations asked participants what they would like to do that day. In this way, participants could suggest activities that they preferred. While participants set the activities and "the program of the day" at the green care farm, there were few plans by the end of breakfast at the regular day care other than those activities that had been scheduled previously, e.g. music activities and meals. As a result, participants at the regular day care spent a lot of time waiting for something to happen while the staff tidied up after meals and between the scheduled activities. Some of the participants fell asleep sitting on the sofa after morning gatherings or meals. Three of them smoked, and they frequently went to the patio.

\subsubsection{Activities}

The third category, activities, has two sub-categories describing how activities are influenced by place and how they function as a catalyst for everyday life in day care services in addition to giving place meaning to some degree. Both day care services stated that their aim was to provide meaningful days for participants. In both day care services, staff and participants eat breakfast and dinner together, gathering around a kitchen table. Different kinds of activities take place during the day, such as reading aloud from the newspaper, knitting, playing games like Hoopla and dice games, baking, feeding the animals, and so on.

1) Active in daily activities

At the green care farm, everyone participated in the daily activities throughout the day such as preparing meals (all meals were made from scratch, even the dinner), cleaning up after meals, making crispbread or baking cakes, or hanging up laundry to dry. Knitting was also one of the activities, and during this activ- 
ity, one of the staff members often read aloud from a magazine or everyone listened to old record albums. Some of the participants at the green care farm preferred to be in the stable, e.g. feeding the animals, grooming the horses, mucking out stalls, or driving a horse and carriage.

Bert (a participant) is on his way out to the stable to feed the cats, when Mary (another participant) asks him if she can join him. She wants to visit the goats. Cathy, one of the staff, says that she can go with them. She picks up a paper bag with peels and other food wastes and gives it to Mary. "You can bring this to the goats," she says. Mary gives her a big smile and walks out.

In the stable, several cats have their home. In a small room, behind a curtain, Bert finds an empty plate, and he pours out some of the cat food. Then he fills a bowl with fresh water. Two cats are now walking around his feet, and he bends down to pet them. (...) Cathy follows Mary to the goats. Mary opens the bag and empties it in the tray (...) and after a while she wants to go back. In the stable, Bert now pets one of the mares. Mary climbs up in the sofa and the stallion nips her hair as she tries to rise up. She laughs aloud and tells him to stop while she reaches her hands over her head. Cathy walks over quickly to give Mary a hand. When Mary now stands on the sofa, she can reach the stallion and she embraces his neck, telling him what a beautiful boy he is.

Participants expressed on several occasions that they felt useful and that they made a valuable contribution to everyday life at the farm. By including participants in daily activities such as preparing meals, participants were allowed to use their resources in a variety of ways, and the staff appeared to be flexible and able to organize such activities during the day.

2) Passive in daily activities

At the regular day care, the staff prepared all meals, e.g. at breakfast, staff laid the table and served ready-to-eat sandwiches. In addition, staff member put out slices bread, marmalade and cheese. The participants were invited to sit at the table when the staff had finished their preparations. We did not observe staff including participants in preparing or tidying up after any meals. The regular day care received dinners in vacuum-sealed bags from the central kitchen, which they heated in a special oven. The staff members were not pleased about this because they found it difficult to include the participants in meal preparations, and they mentioned the lack of any smells in the house during dinner preparation. The minimal inclusion of participants in domestic activities was also recognized during activities such as baking buns. One morning, the staff and participants agreed to bake buns to serve at coffee time. The staff tidied up after breakfast, while the participants entered the dayroom.

"In continuing to tidy up, one staff member, Ann, started preparing the dough. None of the participants were invited to take part in this activity at this time. While the dough rose, some of the participants and staff played Hoopla. After the dough had risen, Ann started to knead and roll out the buns. She finished two baking sheets and put them aside to rise before she invited the participants to roll out the rest. The participants were asked to wash their hands 
before starting. One of the participants had to blow his nose, and when he came back, they had finished rolling the buns".

Staff initiated activities such as reading aloud from a newspaper or magazine or playing dice games, and everyone was encouraged to take part. Only on one occasion did we observe a participant taking the initiative to begin an activity.

\section{Discussion}

The aim in this study was to describe the influence of place on everyday life using observations at two different day care services for persons with dementia. The main finding in this study is that the physical and social environments of a place contribute to enabling or inhibiting activities and collaboration between participants and staff. As mentioned, Moore's (2014) Ecological Framework of Place (EFP) refers to four dimensions: the physical environment; people (here, participants and staff in day care services); the program (with a special focus on the rules and routines established in a particular place); and activities that give meaning and value to a place [12]. These four dimensions always interact with each other. In short, we can say that the physical setting, the individual's internal psychological and social processes, and the attributes and activities define a place [33]. In line with Diaz Moore's EFP, it is difficult to discuss the three categories of physical environment, social environment, and activities separately. Rather, what is considered is how these categories give meaning to a place and how place influences persons with dementia in their everyday lives while attending day care services. Thus, we add a main category that emerges from the data: enabling and collaboration in daily life.

\subsection{The Physical Environment's Influence on Daily Activities in Day Care Services}

In both day care services, the physical surroundings influenced the psychosocial environment because they facilitated or hindered activities, social interaction, and psychological well-being. Several studies claim that institutional environments contribute to homogenization and a more effective and medically oriented care approach from the staff, implying a decrease in individuality and choice [11] [23] [34]. Torrington (2006) found in her study that quality of life was shown to be poorer in settings that prioritize safety and health as opposed to those with a more homelike environment [35]. Further, Torrington (2006) claimed that the physical environment should be designed to support activity by providing good physical support that enables activities to take place in a recognizable multi-sensory environment appropriate for their function [35]. Goffman's metaphor (1971) [13] about theatre performance views social interaction as requiring the control of information about the performer. Performances take place in what he calls frontstages. Frontstage, the performers make contact with an audience of others. Behaviour in the frontstage is frequently characterized by politeness and careful attention to rules of decorum. In contrast to this is the backstage, an area where Goffman (1971: 114) claims "suppressed facts can make 
an appearance" and where the impressions created in the frontstage are contradicted, often purposefully [13]. The backstage is hidden from the frontstage audience to a greater or lesser extent. Backstage personal front can be adjusted, or the performer may rehearse a performance or just relax [13]. These conceptualities can explain what kinds of performances the participants in the two different day care services use and how place influences participants' everyday life. The institutional environment in the regular day care with old items, open spaces, and large windows contributed, on the one hand, to a safe environment (e.g. no carpets on the floor, good lightning) and made it easy for participants to find their way in this location. The light from windows and skylights in the roof was helpful during participation in activities, e.g. board or dice games. On the other hand, the participants had to stay in a frontstage position most of the day, with few possibilities to enter a private space, i.e. to go backstage [13]. Foucault (1977) states that surveillance is one of several techniques that aim to control subjects, and it is always connected to space [14]. Therefore, the frequent smoking amongst the participants could be viewed as an attempt to achieve privacy, a "spatial relation", or an effort to achieve the backstage. Still, the participants in the regular day care will always be under surveillance due to the large windows. The large size, uniformity of materials and furnishings, and placement of sofas at each end of the dayroom contributed to less social interaction, as the participants placed themselves in different sofa arrangements or in one of the other chairs placed around the dayroom. In that way, the placement of furniture created barriers for social interaction between both participants and staff in the regular day care environment. At the green care farm with its more intimate placement of furniture, participants placed themselves in a frontstage position, but at the same time, they had several possibilities to go backstage, e.g. by sitting in one of the large armchairs placed in front of the stove or when they went outside for a smoke in the garden. The participants felt a sense of safety and belonging to the place; as one of the participants said, "It's so common here".

\subsection{The Influence of the Social Environment on Daily Activities in Day Care Services}

We discovered what Goffman (1971) defined as regions: “... any place that is bounded to some degree by barriers to perception" [13]. Here, it is not only physical barriers but also other notable barriers, e.g. two or more persons collaborating without inviting significant others present in the setting. The regions can also be woven as sub-regions in a region, e.g. the patio at the regular day care or the stable at the green care farm. In the regular day care, we noticed that the staff established sub-regions, e.g. when they went into the kitchen, preparing meals or tidying up after meals without including the participants. In this way, the staff created barriers that hindered social interaction, but we may also assume that the participants at such moments could enter or behave as though in the backstage, thus achieving some privacy without surveillance or interruption. At any rate, the staff's attention towards the participants' behaviour and placement should be an important aspect during social interaction to facilitate or in- 
crease enabling activities. This attention is also crucial for helping or facilitating meaning-making for the participants, contributing to give place meaning and value, and thereby creating a meaningful day for the participants. Sub-regions were also established at the green care farm, e.g. when one of the staff members and a participant went outside to feed the animals or did other farm-related work in the stable. Meanwhile, these regions did not contribute to the exclusion of either staff or participants. The intimate placement of furniture and sensory impressions, e.g. smells and music from the radio, contributed to natural social interactions and small talk about everyday life or about memories of the olden days when seeing old items, such as the participant who started telling us about how he and his brother shared a bed as children. Social interaction is a dynamic interplay between two or more individuals, where the participants interpret and react to one another's actions. Campo and Chaudhury (2011) found that social factors such as staff work roles and resident group size and physical factors such as a non-institutional character, the nursing station location, and adequate seating and sightlines were influential for prompting or supporting informal social interactions [10]. This aligns with our findings in this study. Old items and decorations, placed around in the regular day care, did not activate dialogue or storytelling, unlike at the green care farm, where participants often recognized and activated memories from childhood when seeing or using old items and were inspired to start conversations with other participants and staff.

\subsection{Dialogue Creates Space for Activities to Emerge}

Architecture and the physical and sensory environment in general influence well-being and what kind of social interactions are possible. The same is also true for persons with dementia in day care services in this study. Both small talk and touching occurred more often in the homelike environment than in the institutional-type environment, while the institutional environment of the regular day care seemed to limit participants' everyday lives by treating them as a homogenized group in an environment that allowed surveillance. In regard to participants' choices to stay in frontstage or backstage positions, the green care farm was able to offer both kinds of spaces, in contrast to the regular day care where participants had to stay "frontstage" most of the time with few if any options to go "backstage" and have a private space, except for using the restrooms. The physical environment of both places influenced the social environment, e.g. social interactions between participants and staff. This seemed to be more evident at the green care farm, with collaboration in activities and conversations serving to create bonds between staff and participants and thereby contributing to an increase in equitable relationships. In contrast, the regular day care, with its routines and scheduled activities, reflected a use of more progressive time, leading to an experience of distance between the participants and staff that was reinforced by staff members wearing uniforms and sometimes nametags. In addition, there are major symbolic elements of control in design. Research on the relationships among ageing, architecture, and built environments claims that arc- 
hitectural space is a vital parameter in creating supportive environments for older people [36] [37], and Kitwood (1997) argued for the importance of the social environment for the functioning of persons with dementia [38]. In using dialogue as an entry to activities and social interaction between participants and between participants and staff in day care services, it becomes central in enabling meaningful activities. The caring approach of staff also becomes central concerning social interaction and collaboration in activities that take place in day care services. People actively create meaningful places through conversation and interaction [39]. Thus, dialouge is essential and staff can demonstrate personcentred ways of working by speaking clearly, and incorporating nonverbal methods of communication, such as the use of facial expressions, eye contact, gestures, posture and the use of touch [10] [40]. Meaning-making involves how we interact with those things that surround us in the life-world, and dementia makes the process of meaning-making difficult [41]. Dialogue between staff and participants is necessary in order to create a fusion of horizons [42]. Further, to help participants make meaning of both the environment and activities, and thereby give place a meaning so they can experience a meaningful daily existence in line with the intentions according to the Norwegian Dementia Plan [43].

\section{Methodological Considerations}

This study focused on describing the influence of place in everyday life in day care services for persons with dementia. Several findings in this study support the findings from previous research. The qualitative method does not seek objectivity but instead seeks to understand people's experiences and must, must act subjectively. There are several limitations of our study. First, this study has a small sample size, with only two day care services using different forms of organization. Malterud et al. (2015) use the concept "information power" [44]. Referring to Malterud (2015), we consider our study to be reasonably strong according to the aim of the study, our sample, the use of established theory, the quality of dialogue and observations, and analysis strategy [44]. If we had made observations over a longer period or in several day care services, we may have managed to gain a larger and broader body of data. However, considering that data were collected in only two day care services, we gathered rich, and thick material, and we assume that there are global perspectives that can be identified from this local example [45]. This approach allowed us to be reflexive in encounters with both day care services [28]. Secondly, participatory observation has the potential to influence behaviour, but concealed observation was not an option from an ethical perspective. Observation data carries with it huge amounts of information that can be difficult to handle and interpret in a systematic manner. Data generation usually involves interpersonal processes, in which the researchers, to varying degrees, have been actors. In the end, decisions about which data material to use and which not to use were made. Hence, the use of two observers in the field at the same time in the first period contributes to the trustworthiness and reliability of what is being observed and, further 
along in the analysis process, which material becomes relevant or irrelevant depending on the aim of the study. Nevertheless, other researchers may have chosen other parts of the data material. This leads us to the next potential issue concerning a researcher's pre-understanding in the field. Field observations as well as other methods of collecting data imply that we, as researchers, should be careful and aware of our own pre-understanding of the field in which we are interested in conducting our research. Pre-understandings were scrutinized, as they influence how text develops during the interview and analysis [42]. Throughout the writing process, all authors discussed this issue repeatedly. Another limitation of this study might be the absence of registered nurses or other professionals with genuine knowledge about dementia diseases working in the day care services. This may have influenced staff routines and programs in the day care services and the staffs' ability to interpret the expression of experiences from the participants [46].

\section{Conclusion}

In the present study, we chose to focus on how place influences everyday life in day care services in relation to how such establishments are organized. The results were discussed in light of Goffman's metaphor of social interaction as performance, and the influence of "backstage" and "frontstage" areas in promoting different social personas, actions, and reactions. We found that different aspects of place influenced participants' ability to engage in active and passive roles at the day care services through enabling and inhibiting activities and collaboration between participants and staff. Place influences the everyday life in day care services due to how such establishments are organized, concerning architecture, physical and social environment, and what kind of activities take place. Therefore, it is important that staff in day care services use dialogue and social interaction as a "start point" and "walk along with" the participants, during collaborations in activities. Having dementia makes the process of meaning-making difficult and it is crucial how staff at the day care services facilitate environment, enable for activities, and communicate with the participants. Day care services that are organized like the green care farm may not be appropriate for persons with allergies, those who have no connections to country living, and those whose physical health may restrict participation in farm-related activities such as feeding animals, and cleaning stables. In contrast, regular day care services have no limits for participants regarding physical health and balance yet may not be a good fit for persons with dementia who have lived in rural areas throughout their lives with strong connections to country life and farms. Hence, day care services should be adjusted to benefit the individual, thus allowing participants to achieve a meaningful day according to their own needs in line with a person-centred approach.

\section{Acknowledgements}

The authors would like to thanks participants who made this study possible. 


\section{References}

[1] Knapp, M., Comas-Herrera, A., Somani, A. and Banerjee, S. (2007) Dementia: International Comparisons. Summary Report for the National Audit Office. Personal Social Services Research Unit, London School of Economics and Political Science and the Institute of Psychiatry, Kings College, London, England. www.pssru.ac.uk

[2] Brodaty, H. and Donkin, M. (2009) Family Caregivers of People with Dementia. Dialogues in Clinical Neuroscience, 11, 217-228.

[3] Andren, S. and Elmståhl, S. (2008) The Relationship between Caregiver Burden, Caregiver's Perceived Health and Their Sense of Coherence in Caring for Elders with Dementia. Journal of Clinical Nursing, 17, 790-799. https://doi.org/10.1111/j.1365-2702.2007.02066.x

[4] Fields, N.L., Anderson, K.A. and Dabelko-Schoeny, H. (2014) The Effectiveness of Adult Day Services for Older Adults: A Review of the Literature from 2000 to 2011. Journal of Applied Gerontology, 33, 130-163. https://doi.org/10.1177/0733464812443308

[5] Myren, G.E.S., Enmarker, I., Saur, E. and Hellzen, O. (2013) Relatives' Experiences of Everyday Life When Receiving Day Care Services for Persons with Dementia Living at Home. Health, 5, 1227-1235. https://doi.org/10.4236/health.2013.58166

[6] Myren, G.E.S., Enmarker, I., Saur, E. and Hellzen, O. (2015) Being Free Like a Bird-The Meaning of Being an Informal Caregiver for Persons with Dementia Who Are Receiving Day Care Services. Open Journal of Nursing, 5, 109-119. https://doi.org/10.4236/ojn.2015.52013

[7] Anderson, K.A., Dabelko-Schoeny, H.I., Fields, N.L. and Carter, R.J. (2015) Beyond Respite: The Role of Adult Day Services in Supporting Dementia Caregivers. Home Health Care Services Quarterly, 34, 101-112. https://doi.org/10.1080/01621424.2015.1040939

[8] Van Haeften-Van Dijk, A.M., Meiland, F.J.M.,Van Mierlo, L.D. and Dröes, R.M. (2015) Transforming Nursing Home-Based Day Care for People with Dementia into Socially Integrated Community Day Care: Process Analysis of the Transition of Six Day Care Centres. International Journal of Nursing Studies, 52, 1310-1322. https://doi.org/10.1016/j.ijnurstu.2015.04.009

[9] Tretteteig, S., Vatne, S. and Rokstad, A.M.M. (2016) The Influence of Day Care Centres for People with Dementia on Family Caregivers: An Integrative Review of the Literature. Aging \& Mental Health, 20, 450-462. https://doi.org/10.1080/13607863.2015.1023765

[10] Campo, M. and Chaudhury, H. (2011) Informal Social Interaction among Residents with Dementia in Special Care Units: Exploring the Role of the Physical and Social Environments. Dementia, 11, 401-423. https://doi.org/10.1177/1471301211421189

[11] Goffman, E. (1968) Asylums: Essays on the Social Situation of Mental Patients and Other Inmates. Penguin, Harmondsworth.

[12] Diaz Moore, K. (2014) An Ecological Framework of Place: Situating Environmental Gerontology within a Life Course Perspective. International Journal of Aging Human Development, 79, 183-209. https://doi.org/10.2190/AG.79.3.a

[13] Goffman, E. (1971) The Presentation of Self in Everyday Life. Pelican Books, London.

[14] Foucault, M. (1977) Discipline and Punish: The Birth of the Prison. Penguin Books, London.

[15] Pomeroy, S.H., Scherer, Y., Runkawatt, V., Iamsumang, W., Lindemann, J. and Resnick, B. (2011) Person Environment Fit and Functioning among Older Adults in 
a Long-Term Care Setting. Geriatric Nursing, 32, 368-378. https://doi.org/10.1016/j.gerinurse.2011.07.002

[16] Wiersma, E. and Dupuis, S.L. (2010) Becoming Institutional Bodies: Socialization into a Long-Term Care Home. Journal of Aging Studies, 24, 278-291.

https://doi.org/10.1016/j.jaging.2010.08.003

[17] Diaz Moore, K. (1999) Dissonance in the Dining Room: A Study of Social Interaction in a Special Care Unit. Qualitative Health Research, 9, 133-155. https://doi.org/10.1177/104973299129121640

[18] Liou, C.-L. and Jarrott, S.E. (2013) Taiwanese Experiences: Elders with Dementia in Two Different Adult Day Service (ADS) Environments. Aging \& Mental Health, 17, 942-951. https://doi.org/10.1080/13607863.2013.788998

[19] Salari, S.M. (2006) Infantilization as Elder Mistreatment: Evidence from Five Adult Day Centers. Journal of Elder Abuse \& Neglect, 17, 53-91. https://doi.org/10.1300/J084v17n04_04

[20] Diaz Moore, K. (2004) Interpreting the "Hidden Program" of a Place: An Example from Dementia Day Care. Journal of Aging Studies, 18, 297-320. https://doi.org/10.1016/j.jaging.2004.03.004

[21] Salari, S., Brown, B.B. and Eaton, J. (2006) Conflicts, Friendship Cliques and Territorial Displays in Senior Center Environments. Journal of Aging Studies, 20, 237252. https://doi.org/10.1016/j.jaging.2005.09.004

[22] Orrell, A., McKee, K., Torrington, J., Barnes, S., Darton, R., Netten, A. and Lewis, A. (2013) The Relationship between Building Design and Residents' Quality of Life in Extra Care Housing Schemes. Health \& Place, 21, 52-64. https://doi.org/10.1016/j.healthplace.2012.12.004

[23] Schmitt, E.M., Sands, L.P., Weiss, S., Dowling, G. and Covinsky, K. (2010) Adult Day Health Center Participation and Health-Related Quality of Life. The Gerontologist, 50, 531-540. https://doi.org/10.1093/geront/gnp172

[24] Peace, S.M., Holland, C. and Kellaher, L. (2005) Making Space for Identity. In: Andrews, G.J. and Philips, D.R., Eds., Ageing and Place: Perspectives, Policy, Practice, Routledge, Abingdon, 188-204.

[25] Ryvicker, M. (2009) Preservation of Self in the nursing Home: Contradictory Practices within Two Models of Care. Journal of Aging Studies, 23, 12-23. https://doi.org/10.1016/j.jaging.2007.09.004

[26] Smith, A.E. (2009) Ageing in Urban Neighbourhoods: Place Attachment and Social Exclusion. University of Bristol, Bristol.

[27] Polit, D.F. and Beck, C.T. (2004) Nursing Research: Principles and Methods. Lippincott Williams \& Wilkins, Philadelphia.

[28] Sarah, P. (2015) Doing Sensory Ethnography. 2nd Edition, Sage, Los Angeles.

[29] Thoresen, L. and Ôhlen, J. (2015) Lived Observations: Linking the Researcher's Personal Experiences to Knowlegde Development. Qualitative Health Research, 25, 1589-1598. https://doi.org/10.1177/1049732315573011

[30] World Medical Association Declaration (2002) World Medical Association Declaration of Helsinki: Ethical Principles for Medical Research Involving Human Subjects. Journal of Postgraduate Medicine, 48, 206-208.

[31] Graneheim, U.H. and Lundman, B. (2004) Qualitative Content Analysis in Nursing Research: Concepts, Procedures and Measures to Achieve Trustworthiness. Nurse Education Today, 24, 105-112. https://doi.org/10.1016/j.nedt.2003.10.001

[32] Sandelowski, M. (2000) Focus on Research Methods. Whatever Happened to Qualitative Description? Research in Nursing \& Health, 23, 334-340. 
https://doi.org/10.1002/1098-240X(200008)23:4<334::AID-NUR9>3.0.CO;2-G

[33] Shamsuddina, S. and Ujangb, N. (2008) Making Places: The Role of Attachment in Creating the Sense of Place for Traditional Streets in Malaysia. Habitat International, 32, 399-409. https://doi.org/10.1016/j.habitatint.2008.01.004

[34] Davis, S., Byers, S., Nay, R. and Koch, S. (2009) Guiding Design of Dementia Friendly Environments in Residential Care Settings: Considering the Living Experiences. Dementia, 8, 185-203. https://doi.org/10.1177/1471301209103250

[35] Torrington, J. (2006) What Has Architecture Got to Do with Dementia Care? Explorations of the Relationship between Quality of Life and Building Design in Two EQUAL Projects. Quality in Ageing and Older Adults, 7, 34-48. https://doi.org/10.1108/14717794200600006

[36] Cutler, L.J. (2007) Physical Environments of Assisted Living: Research Needs and Challenges. The Gerontologist, 47, 68-82. https://doi.org/10.1093/geront/47.Supplement_1.68

[37] Diaz Moore, K., Van Haitsmab, K., Curytob, K. and Saperstein, A. (2003) Pragmatic Environmental Psychology: A Metatheoretical Inquiry into the Work of M. Powell Lawton. Journal of Environmental Psychology, 23, 471-482. https://doi.org/10.1016/S0272-4944(02)00116-0

[38] Kitwood, T. (1997) The Experience of Dementia. Aging \& Mental Health, 1, 13-22. https://doi.org/10.1080/13607869757344

[39] Stokowski, P.A. (2002) Languages of Place and Discourses of Power: Constructing New Senses of Place. Journal of Leisure Research, 34, 368-382.

[40] Veselinova, C. (2014) Influencing Communication and Interaction in Dementia. Nursing \& Residential Care, 16, 162-166. https://doi.org/10.12968/nrec.2014.16.3.162

[41] Widdershoven, G.A.M. and Berghmans, R.L.P. (2001) Advance Directives in Dementia Care: From Instruction to Instruments. Patients Education and Counseling, 44, 179-186. https://doi.org/10.1016/S0738-3991(00)00190-7

[42] Gadamer, H.J. (1993) Truth and Method. Sheed and Ward, London.

[43] Demensplan 2020. (2015) Norwegian Ministry of Health and Care Services, Oslo.

[44] Malterud, K., Siersma, V.D. and Guassora, A.D. (2015) Sample Size in Qualitative Interview Studies: Guided by Information Power. Qualitative Health Research, 26, 1753-1760. https://doi.org/10.1177/1049732315617444

[45] Hamel, J. (1993) Case Study Methods. Sage, Newbury Park. https://doi.org/10.4135/9781412983587

[46] Ericsson, I., Hellström, I. and Kjellström, E. (2011) Sliding Interactions: An Ethnography about How Dementia Interacts in Housing with Care for the Elderly. Dementia, 10, 523-538. https://doi.org/10.1177/1471301211409376 
Submit or recommend next manuscript to SCIRP and we will provide best service for you:

Accepting pre-submission inquiries through Email, Facebook, LinkedIn, Twitter, etc. A wide selection of journals (inclusive of 9 subjects, more than 200 journals)

Providing 24-hour high-quality service

User-friendly online submission system

Fair and swift peer-review system

Efficient typesetting and proofreading procedure

Display of the result of downloads and visits, as well as the number of cited articles Maximum dissemination of your research work

Submit your manuscript at: http://papersubmission.scirp.org/

Or contact health@scirp.org 